\title{
Strategi Pengembangan Peran Penyuluh Pertanian Lapang di Provinsi Banten
}

\section{The Strategy of Role Development of Agriculture Extension Agent InBanten}

\author{
Narso $^{1}$, Amiruddin Saleh ${ }^{2}$, Pang S Asngari ${ }^{2}$, dan Pudji Muljono ${ }^{2}$ \\ ${ }^{1}$ Universitas Ibnu Chaldun Jakarta \\ 2 Departemen Sains Komunikasi dan Pengembangan Masyarakat, \\ Fakultas Ekologi Manusia, Institut Pertanian Bogor, Bogor
}

\begin{abstract}
This research aim was to formulate priority of strategy development the role of agriculture extension agent in Banten. To determine the priority of strategy development the role of agriculture extension agent used SWOT and AHP. Result of research indicated that the priority of development Strategy of role the agriculture extension agent in Banten were: (1) Improving the quality of human resouces of extension agent by diklat from other institution to get the ability, knowledge, and skill; (2) Improving of quality of counselling and cooperation with the relevant institution by the existence of fundamental duty clarity and function; (3) Product marketing competitive agriculture by maximizing role of group of farmer; (4) Optimalization of agriculture development with the guarantee of invitation regulation; and (5) Exploiting technology to support the agriculture extinsion program.
\end{abstract}

Keywords: strategy, role, development, agriculture extension agent

Abstrak

Penelitian ini bertujuan untuk merumuskan prioritas strategi pengembangan peran penyuluh pertanian di Banten. Untuk menentukan prioritas strategi pengembangan peran penyuluh pertanian digunakan SWOT dan AHP. Hasil penelitian menunjukkan bahwa prioritas Strategi pengembangan peran penyuluh pertanian di Banten adalah: (1) Meningkatkan kualitas sumber daya manusia penyuluh oleh diklat dari instansi lain untuk mendapatkan kemampuan, pengetahuan, dan keterampilan; (2) Meningkatkan kualitas konseling dan kerjasama dengan instansi terkait dengan adanya kejelasan tugas pokok dan fungsi; (3) pemasaran produk pertanian yang kompetitif dengan memaksimalkan peran kelompok tani; (4) Optimalisasi pembangunan pertanian dengan jaminan regulasi undangan; dan (5) teknologi Pemanfaatan untuk mendukung program penyuluhan pertanian.

Kata kunci: strategi, peran, pembangunan, agen penyuluhan pertanian

\section{Pendahuluan}

Tujuan penyuluhan pertanian adalah dalam rangka menghasilkan SDM pelaku pembangunan pertanian yang kompeten sehingga mampu mengembangkan usaha pertanian yang tangguh, bertani lebih baik (better farming), berusaha tani lebih menguntungkan (better business), hidup lebih sejahtera (better living), dan lingkungan lebih sehat. Penyuluhan pertanian dituntut agar mampu menggerakkan masyarakat, memberdayakan petani-nelayan, pengusaha pertanian dan pedagang pertanian, serta mendampingi petani untuk membantu menganalisis situasi-situasi yang sedang mereka hadapi dan melakukan perkiraan ke depan, membantu mereka menemukan masalah, membantu mereka memperoleh pengetahuan/ informasi guna memecahkan masalah, membantu mereka mengambil keputusan, dan membantu mereka menghitung besarnya risiko atas keputusan yang diambilnya serta peran lain yang berhubungan langsung dengan kegiatan petani secara umum.

Pembangunan pertanian dewasa ini telah diarahkan menuju industrialisasi di bidang pertanian melalui pengembangan agribisnis yang berkelanjutan dan berwawasan lingkungan. Hal ini akan bisa diwujudkan dengan lebih dahulu menciptakan sumberdaya manusia yang berkualitas, terutama masyarakat pertanian, sehingga kesinambungan dan ketangguhan petani dalam pembangunan pertanian bukan saja diukur dari kemampuan petani dalam memanage usahanya sendiri, tetapi juga ketangguhan dan kemampuan petani dalam mengelola sumberdaya alam secara rasional dan

${ }^{1}$ Korespondensi penulis 
efisien, berpengetahuan, terampil, cakap dalam membaca peluang pasar dan mampu menyesuaikan diri terhadap perubahan dunia khususnya perubahan dalam pembangunan pertanian. Di sinilah pentingnya penyuluhan pertanian untuk membangun dan menghasilkan SDM yang berkualitas.

Oleh karena itu, sudah selayaknya peran penyuluhan pertanian ditempatkan pada posisi yang strategis dalam sebuah kelembagaan yang didukung oleh kebijakan pemerintah, sehingga penyelenggaraan penyuluhan pertanian betul-betul bisa berjalan efektif dan efisien.Pembangunan pertanian merupakan bagian terpenting dari pembangunan sebagian besar daerah di Indonesia dan untuk membangunnya perlu ditunjang dengan SDM yang berkualitas.

Menurut Yayasan Pengembangan Sinar Tani (2001) sepanjang sejarah penyuluhan, peran penyuluh pertanian berubah ubah sesuai dengan kebijakan, pendekatan dan strategi penyuluhan yang ditetapkan oleh pemerintah. Sejak didirikannya penyuluhan dengan nama Landbouw Voorlichting Dienst (LVD) pada jaman penjajahan Belanda tahun 1910, penyuluh sudah berperan sebagai tenaga teknis penyuluhan. Mardikanto (2009) mengemukakan bahwatujuan penyuluhan dengan menggunakan metode "olivlek" hanya ditujukan pada beberapa petani yang memiliki sumberdaya untuk meningkatkan produksi saja, seperti para kontak tani dan petani-petani demonstrator pada daerah terbatas.

Seiring dengan perubahan paradigma pembangunan pertanian yang lebih mengutamakan pembangunan manusianya, maka peran penyuluh pertanian dalam menyukseskan terjadinya perubahan pola perilaku petani menjadi semakin penting. Menurut Padmowihardjo (2004), tujuan penyuluhan pertanian adalah menghasilkan manusia pembelajar, manusia penemu ilmu dan teknologi, manusia pengusaha agribisnis yang unggul, manusia pemimpin di masyarakatnya, manusia guru bagi petani lain, yang bersifat mandiri dan interdependensi, karena itu penyuluhan adalah proses pembelajaran dan proses pemberdayaan.

Penyuluh pertanian adalah orang yang mengemban tugas memberikan dorongan kepada para petani agar mau mengubah cara berpikir, cara kerja dan cara hidupnya yang lama dengan cara-cara baru yang lebih sesuai dengan perkembangan zaman dan perkembangan teknologi pertanian yang lebih maju (Kartasapoetra, 1994). Padmowihardjo (1994) menjelaskan bahwa penyuluh pertanian adalah "pemandu" yang memandu petani, pengusaha dan pedagang untuk menemukan ilmu dan teknologi yang mereka butuhkan untuk memecahkan masalah yang mereka hadapi. Dalam proses kepemanduan, petani, pengusaha dan pedagang pertanian bukan sebagai "murid" tetapi "mitra belajar" yang melakukan proses belajar. Hasilnya adalah petani, pengusaha dan pedagang pertanian yang berkualifikasi sebagai manusia pembe-lajar, manusia peneliti, manusia penyelenggara agribisnis, manusia pemimpin, dan manusia pemandu petani/pengusaha/pedagang lainnya. Petani dirangsang untuk belajar agar menjadi berdaya untuk memecahkan masalahnya sendiri.

Menurut Rogers (2003), penyuluh adalah seseorang yang atas nama pemerintah atau lembaga penyuluhan berkewajiban untuk mempengaruhi proses pengambilan keputusan yang dilakukan oleh sasaran penyuluhan untuk mengadopsi inovasi. Berdasarkan definisi tersebut, Mardikanto (2009) mengatakan bahwa peran penyuluh tidak hanya terbatas menyampaikan inovasi dan mempengaruhi proses pengambilan keputusan oleh sasaran penyuluhan, akan tetapi seorang penyuluh harus mampu menjadi jembatan penghubung antara pemerintah atau lembaga penyuluhan yang diwakilinya dengan masyarakat sasaran, baik dalam hal menyampaikan inovasi atau kebijakankebijakan yang harus diterima dan dilaksanakan oleh masyarakat sasaran, maupun untuk menyampaikan umpan balik atau tanggapan masyarakat kepada pemerintah atau lembaga penyuluhan yang bersangkutan.

Menurut Mosher (1987), setiap penyuluh pertanian harus mampu melaksanakan peran sebagai: (a) guru: untuk mengubah perilaku masyarakat sasarannya; (b) penganalisis: dengan melakukan pengamatan terhadap keadaan dan masalahmasalah serta kebutuhan masyarakat sasaran yang dilanjutkan dengan analisis tentang alternatif pemecahan masalahnya; (c) penasehat: dengan memberikan pertimbangan kepada masyarakat sasaran dalam memilih alternatif yang tepat; dan (d) organisator: mampu menjalin hubungan baik dengan segenap lapisan masyarakat, mampu menumbuhkan kesadaran dan menggerakkan partisipasi 
masyarakat, mampu berinisiatif bagi terciptanya perubahan-perubahan serta dapat memobilisasi sumberdaya, mengarahkan dan membina kegiatankegiatan maupun mengembangkan kelembagaan yang efektif.

Menurut Kurt Lewin (Mardikanto, 2009), terdapat tiga macam peran penyuluh yang terdiri atas kegiatan-kegiatan: (1) pencairan diri dengan masyarakat sasaran, (2) menggerakkan masyarakat untuk melakukan perubahan-perubahan, dan (3) pemantapan hubungan dengan masyarakat sasaran. Agar lebih profesional maka seorang penyuluh harus berperan sebagai: pembawa informasi, pendengar yang baik, motivator, fasilitator proses, agen penghubung, pembentuk kemampuan, guru keterampilan, work helper, pengelola program, pekerja kelompok, penjaga batas, promoter, pemimpin lokal, konsultan, protektor dan pembentuk lembaga (Lionberger \& Gwin, 1982).

Menurut Lippitt et al., (1958), peranan agen pembaruan yang akan memberikan kontribusi terhadap proses perubahan adalah: (a) menjembatani dan merangsang relasi baru dalam sistem klien, (b) menceriterakan pengalamannya dalam menyampaikan teknik-teknik baru, (c) menimbulkan kekuatan dari dalam, (d) menciptakan lingkungan yang khusus, dan (e) memberikan dukungan selama proses perubahan berlangsung. Penelitian ini bertujuan untuk merumuskan prioritas strategi pengembangan peran PPL dalam menjalankan aktivitas penyuluhan di Provinsi Banten Penelitian ini dirancang dengan metode survei deskriptifkorelasional.

\section{Metode Penelitian}

Penelitian dilaksanakan pada Bulan April hingga Agustus 2011 di empat kabu-paten Provinsi Banten, yaitu Kabupaten Lebak, Kabupaten Pandeglang, Kabupaten Serang, dan Kabupaten Tangerang. Lokasi penelitian dipilih mengingat Provinsi Banten merupakan daerah pemekaran baru yang memiliki potensi pertanian yang cukup baik.

Populasi dalam penelitian ini adalah seluruh penyuluh pertanian PNS yang ada di Provinsi Banten. Menurut data dari Kementerian Pertanian 2011, jumlah penyuluh PNS yang ada di Provinsi Banten adalah 345 orang yang tersebar di empat kabupaten, yaitu Kabupaten Lebak 70 orang,
Kabupaten Pandeglang 105 orang, Kabupaten Serang 92 orang, dan Kabupaten Tangerang 78 orang. Penarikan sampel menggunakan teknik simplerandom sampling yang diproporsikan sesuai jumlah penyuluh di masing-masing lokasi.

Besarnya jumlah sampel ditentukan dengan menggunakan rumus Slovin (Sevilla, 1993), yaitu:

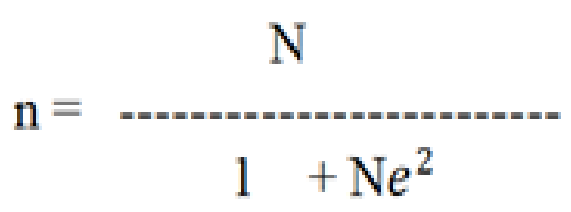

Keterangan: $\mathrm{n}=$ besarnya sampel

$\mathrm{N}=$ besarnya populasi

$\mathrm{e}=$ batas error $(8 \%)$

Batas eror yang digunakan adalah delapan persen, sehingga dengan menggunakan rumus di atas, jumlah sampel dalam penelitian ini adalah 107,54 atau 110 orang. Data jumlah sampel berdasarkan proporsi populasi di masing-masing kabupaten disajikan pada Tabel 1. Untuk menentukan prioritas strategi pengembangan peran penyuluh pertanian digunakan analisis SWOT dan analisis AHP. Menurut Rangkuti (2008), analisis SWOT adalah identifikasi berbagai faktor secara sistematis untuk merumuskan strategi korporasi. Analisis ini didasarkan pada logika yang dapat memaksimalkan kekuatan (strenghts) dan peluang (opportunities), namun secara bersamaan dapat meminimalkan kelemahan (weaknesses) dan ancaman (threats). Proses penyusunan rencana strategis melalui tiga tahap analisis, yaitu: (1) pengumpulan data, (2) analisis data, dan (3) pengambilan keputusan. Pengumpulan data dilakukan dengan melibatkan berbagai pihak terkait seperti penyuluh, LSM, ketua kelompok tani, dan pemerintah setempat. Analisis berjenjang

Tabel 1 Data Sampel Penelitian

\begin{tabular}{clcc}
\hline No & Lokasi Penelitian & $\begin{array}{c}\text { Populasi } \\
\text { (orang) }\end{array}$ & $\begin{array}{c}\text { Sampel } \\
\text { (orang) }\end{array}$ \\
\hline 1 & Kabupaten Lebak & 70 & 22 \\
2 & Kabupaten Pandeglang & 105 & 33 \\
3 & Kabupaten Serang & 92 & 30 \\
4 & Kabupaten Tangerang & 78 & 25 \\
\hline Jumlah & 345 & 110 \\
\hline
\end{tabular}


(analytic hierarchy process/AHP) bertujuan untuk menentukan skala prioritas atas alternatif pilihan berdasarkan suatu proses analitis secara berjenjang dan terstruktur atas variabel keputusan (Dermawan, 2009).

\section{Hasil dan Pembahasan}

\section{Analisis Strategi Pengembangan Peran Penyuluh}

Analisis SWOT digunakan untuk menentukan strategi pengembangan peran penyuluh pertanian dalam menjalankan aktivitas penyuluhan di Provinsi Banten.Analisis SWOT dilakukan atas dasar logika yang dapat memaksimalkan kekuatan (strengths) dan peluang (opportunities), namun secara bersamaan dapat meminimalkan kelemahan (weaknesses) dan ancaman (threats).

\section{Matriks Analisis Internal}

Faktor-faktor internal meliputi kekuat-an dan kelemahan yang telah diidentifikasi, disusun dalam suatu matriks IFAS (internal strategic factor analysis summary). Hasil analisis internal strategi pengembangan peran penyuluh pertanian di Provinsi
Banten disa-jikan dalam Tabel 2. Hasil analisis internal sebagaimana ditampilkan dalam Tabel 2 menunjukkan bo-bot skor kekuatan adalah 1,85 dan bobot skor kelemahan adalah 1,45. Berdasarkan hasil tersebut diperoleh selisih internal (kekuatan dan kelemahan) adalah 0,40 . Hal ini berarti bahwa secara internal, kondisi penyuluh pertanian lapang di Provinsi Banten memiliki kekuatan yang lebih dominan dibanding kelemahan, atau dengan kata lain bahwa secara internal penyuluh memiliki potensi yang lebih baik dalam upaya untuk meningkatkan peran mereka dalam aktivitas penyuluhan.

\section{Matriks Analisis Eksternal}

Faktor-faktor enternal meliputi peluang dan ancama yang telah diidentifikasi, disusun dalam suatu matriks EFAS (eksternal strategic factor analysis summary). Hasil analisis eksternal strategi pengembangan peran penyuluh pertanian di Provinsi Banten disajikan dalam Tebel 3. Hasil analisis eksternal sebagaimana ditampilkan dalam Tabel 3 menunjukkan bahwa faktor peluang memiliki bobot skor 1,7 sedangkan faktor ancaman memiliki bobot skor 1,48. Dengan demikian, hasil analisis eksternal yang menunjukkan selisih antara faktor peluang dan ancaman adalah sebesar 0,22. Hal tersebut

Tabel 2 Analisis Internal Peran Penyuluh Pertanian di Provinsi Banten

\begin{tabular}{clrcc}
\hline No & \multicolumn{1}{c}{ Kekuatan (S) } & Rating & Bobot & Bobot Skor \\
\hline 1 & Memiliki program penyuluhan yang jelas & 4,00 & 0,100 & 0,40 \\
2 & Setiap PPL memiliki petani binaan & 3,50 & 0,100 & 0,35 \\
3 & Adanya UU No. 16/2006 tentang tugas pokok penyuluh & 3,25 & 0,100 & 0,33 \\
4 & Penyuluh memiliki pengetahuan, kemampuan dan keterampilan & 3,75 & 0,100 & 0,38 \\
5 & Penyuluh memiliki tugas pokok dan fungsi yang jelas & 4,00 & 0,100 & 0,40 \\
& Total S & & 0,500 & 1,85 \\
& Kelemahan (W) & & & \\
1 & Kurangnya tenaga penyuluh & 4,00 & 0,072 & 0,29 \\
2 & Kurangnya dana penyuluh & 3,00 & 0,071 & 0,21 \\
3 & Kurangnya sarana dan prasarana penyuluhan & 3,25 & 0,072 & 0,23 \\
4 & Kurangnya pengakuan tenaga fungsional penyuluh & 3,00 & 0,072 & 0,21 \\
5 & Kurangnya koordinasi dengan unit terkait & 2,25 & 0,071 & 0,16 \\
6 & Adanya penggabungan organisasi penyuluh dengan pemberdayaan & 2,50 & 0,071 & 0,18 \\
7 & Kurang harmonis dengan unit kerja internal & 2,25 & 0,071 & 0,16 \\
& Total W & & 0,500 & 1,45 \\
& Total Internal & & 1,000 & 3,30 \\
& Selisih Internal (S - W) & & & 0,40 \\
\hline
\end{tabular}


Tabel 3 Analisis Eksternal Peran Penyuluh Pertanian di Provinsi Banten

\begin{tabular}{clrrr}
\hline No & \multicolumn{1}{c}{ Peluang (O) } & Rating & Bobot & Skor \\
\hline 1 & Adanya kerjasama antar instansi terkait & 3,25 & 0,10 & 0,325 \\
& Adanya kesempatan mengikuti diklat di lain instansi untuk menambah & & & \\
2 & wawasan & 2,75 & 0,10 & 0,275 \\
& Adanya pemasaran produk dari hasil pertanian & 4,00 & 0,10 & 0,40 \\
4 & Adanya perkembangan teknologi di bidang pertanian & 3,75 & 0,10 & 0,375 \\
5 & Adanya lahan persawahan yang memadai & 3,25 & 0,10 & 0,325 \\
& Total O & & 0,50 & 1,70 \\
\hline No & \multicolumn{1}{c}{ Ancaman (T) } & Rating & Bobot & Skor \\
\hline 1 & Adanya kebijakan otonomi daerah & 3,25 & 0,063 & 0,20 \\
2 & Adanya PP No 41 th 2004 & 3 & 0,063 & 0,19 \\
3 & Pendistribusian pupuk kurang merata dari pemerintah & 2,75 & 0,062 & 0,17 \\
4 & Para pekerja tani beralih ke sector produksi & 2,5 & 0,06 & 0,16 \\
5 & Kurangnya kerjasama antar instansi terkait & 2,75 & 0,063 & 0,17 \\
6 & Adanya perubahan iklim yang kurang menentu & 3,75 & 0,063 & 0,23 \\
7 & Adanya penyakit hama wereng & 3 & 0,063 & 0,19 \\
8 & Adanya persaingan produk lokal & 2,75 & 0,063 & 0,17 \\
& Total T & & 0,50 & 1,48 \\
& Total Eksternal & & 1 & 3,18 \\
& Selisih Eksternal (O - T) & & & 0,22 \\
\hline
\end{tabular}

berarti bahwa penyuluh pertanian lapang di Provinsi Banten memiliki peluang yang lebih baik dibanding ancaman dalam upaya meningkatkan perannya untuk menjalankan aktivitas penyuluhan.

Berdasarkan hasil analisis di atas, dapat diidentifikasi posisi strategi pengembangan peran penyuluh dengan nilai internal sebesar 0,40 dan eksternal sebesar 0,22. Dengan demikian, posisi kedua faktor tersebut dapat dilustrasikan dalam Gambar 1. Hasil analisis pada Gambar 1 menunjukkan bahwa posisi strategi peran penyuluh berada di kuadran 1 (S,O).Hal ini berarti bahwa penyuluh memiliki kekuatan dan peluang yang lebih menonjol dibandingkan kelemahan dan ancaman. Oleh karena itu, strategi pengembangan peran yang harus dilakukan adalah berupaya menggunakan kekuatan yang dimiliki dengan memanfaatkan peluang yang ada.Untuk mewujudkan hal tersebut, maka strategi yang menggabungkan kekuatan dan peluang yang dimiliki dapat dirumuskan da-lam Tabel 4.

Berdasarkan Tabel 4, maka rumusan strategi pengembangan peran penyuluh pertanian dalam menjalankan aktivitasnya di Provinsi Banten adalah: (1) Peningkatan kualitas SDM penyuluh dengan mengikuti diklat dari instansi lain untuk menambah kemampuan, pengetahuan, dan keterampilan. (2) Optimalisasi pembangunan pertanian dengan jaminan peraturan perundangan. (3) Pemanfaatan teknologi yang mendukung dan memperlancar pelaksanaan program penyuluhan. (4) Pemasaran produk pertanian yang berdaya saing dengan memaksimalkan peran kelompok tani binaan. (5) Peningkatan kualitas penyuluhan dan sinergitas antar instansi terkait dengan adanya kejelasan tugas pokok dan fungsi.

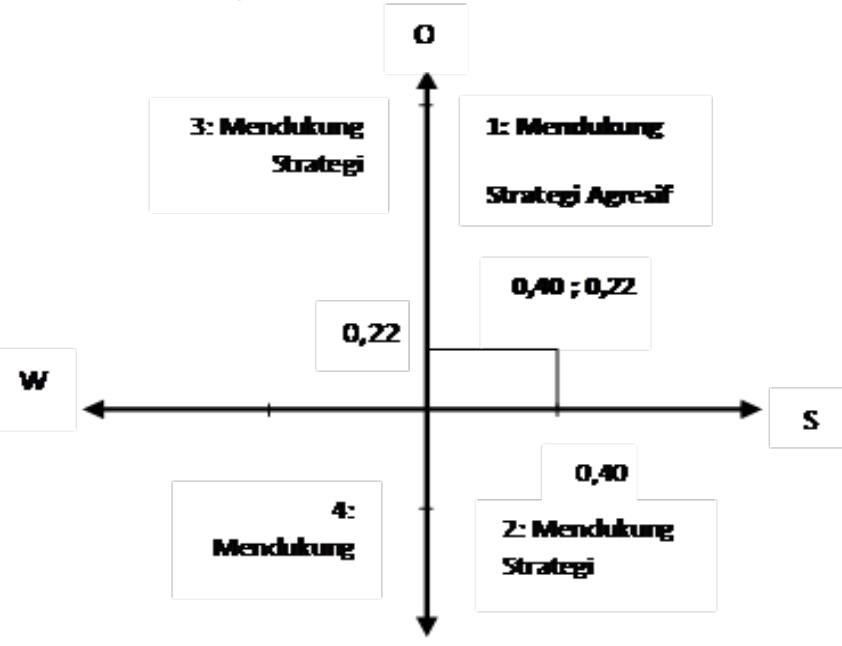

Gambar 1 Diagram analisis SWOT 
Tabel 4 Rumusan Strategi Pengembangan Peran Penyuluh di Provinsi Banten

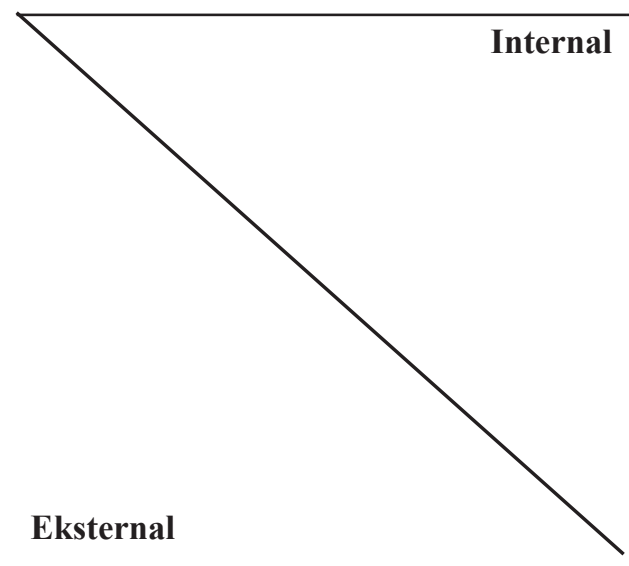

\section{STRENGTHS (S):}

Memiliki program penyuluhan yang jelas

Setiap PPL memiliki petani binaan

Adanya UU No. 16/2006 tentang tugas pokok penyuluh

Penyuluh memiliki pengetahuan, kemampuan dan keterampilan

Penyuluh memiliki tugas pokok dan fungsi yang jelas

\section{WEAKNESSES (W):}

Kurangnya tenaga penyuluh

Kurangnya dana penyuluh

Kurangnya sarana dan prasarana penyuluhan

Kurangnya pengakuan tenaga fungsional penyuluh

Kurangnya koordinasi dengan unit terkait

Adanya penggabungan organisasi penyuluh dengan pemberdayaan

Kurang harmonis dengan unit kerja internal

\section{OPPORTUNITIES (O):}

Adanya kerjasama antar instansi terkait

Adanya kesempatan mengikuti diklat di lain instansi untuk menambah wawasan

Adanya pemasaran produk dari hasil pertanian

Adanya perkembangan teknologi di bidang pertanian

Adanya lahan persawahan yang memadai

\section{Strategi S-0:}

Peningkatan kualitas SDM penyuluh dengan mengikuti diklat dari instansi lain untuk menambah kemampuan, pengetahuan, dan keterampilan (S4,O1, O2)

Optimalisasi pembangunan pertanian dengan jaminan peraturan perundangan $(\mathrm{S} 3, \mathrm{O} 5)$

Pemanfaatan teknologi yang mendukung dan memperlancar pelaksanaan program penyuluhan (S1, O4)

Pemasaran produk pertanian yang berdaya saing dengan memaksimalkan peran kelompok tani binaan $(\mathrm{S} 2, \mathrm{O} 3)$

Peningkatan kualitas penyuluhan dan sinergitas antar instansi terkait dengan adanya kejelasan tugas pokok dan fungsi $(\mathrm{S} 5, \mathrm{O} 1)$

\section{Strategi W-O:}

Kerjasama dengan instansi terkait baik dalam pendanaan, sarana prasarana, maupun SDM untuk mengoptimalkan peran tenaga penyuluh yang ada (W1,W2,W3, W4, O1, $\mathrm{O} 2$ )

Meningkatkan koordinasi antar unit kerja internal agar peran penyuluh lebih optimal dalam melakukan penyuluhan (W5, W7, O3, O5)

Revitalisasi kelembagaan penyuluh agar lebih sesuai dengan perkembangan situasi dan permasalahan yang ada di masyarakat petani $(\mathrm{W} 6, \mathrm{O} 4)$

\section{Threats (T):}

Adanya kebijakan otonomi daerah Adanya PP No 41 th 2004

Pendistribusian pupuk kurang merata dari pemerintah

Para pekerja tani beralih ke sector produksi

Kurangnya kerjasama antar instansi terkait

Adanya perubahan iklim yang kurang menentu

Adanya penyakit hama wereng

Adanya persaingan produk lokal

\section{Strategi S-T:}

Sinkronisasi UU no 16/2006 dengan kebijakan pemerintah daerah dan PP No. 41 th 2004 (O3, $\mathrm{T} 1, \mathrm{~T} 2, \mathrm{~T} 5)$

Optimalisasi peran penyuluh sesuai tugas pokok dan fingsinya dalam memberikan penyuluhan kepada petani $(\mathrm{O} 1, \mathrm{O} 5, \mathrm{~T} 3, \mathrm{~T} 8)$

Meningkatkan pembinaan kepada petani terutama dalam mengatasi berbagai persoalan teknik pertanian $(\mathrm{O} 2, \mathrm{O} 4, \mathrm{~T} 4, \mathrm{~T} 6, \mathrm{~T} 7)$

\section{Strategi W-T:}

Meningkatkan peran penyuluh swadaya dan petani inovator $(\mathrm{W} 1, \mathrm{~T} 1, \mathrm{~T} 2)$

Mendorong pemerintah daerah agar lebih proporsional dalam menunjang kinerja aparat khususnya penyuluh pertanian agar dapat melaksanakan perannya dengan optimal (W2, W3, W4, T1).

Menciptakan harmonisasi antar unit organisasi khususnya penyuluhan dan pemberdayaan agar dapat memberikan penyuluhan yang baik kepada petani (W5, W6, W7, T3, T4, T5, T6, T7, T8) 
Jurnal Penyuluhan, September 2012 Vol. 9 No. 2

Tabel 5 Analisis Prioritas Faktor-faktor Penentu Strategi

\begin{tabular}{lccccc}
\hline \multicolumn{1}{c}{ Faktor } & Dana & Kebijakan & SDM & Sarana-prasana & Total Priority Value \\
\hline Dana & 0,24 & 0,24 & 0,24 & 0,24 & 0,98 \\
Kebijakan & 0,26 & 0,26 & 0,26 & 0,26 & 1,02 \\
SDM & 0,27 & 0,27 & 0,27 & 0,27 & 1,07 \\
Sarana-prasarana & 0,23 & 0,23 & 0,23 & 0,23 & 0,93 \\
\hline
\end{tabular}

Analisis Prioritas Strategi Pengembangan Peran Penyuluh

Teknik analisis yang digunakan untuk menentukan prioritas strategi pengembangan peran penyuluh di Provinsi Banten adalah teknik proses analisis berjenjang atau analytic hierarchy process (AHP). Ciri khas model ini adalah penentuan skala prioritas atas alternatif pilihan berdasarkan suatu proses analitis secara berjenjang, terstruktur atas variabel keputusan.

Implementasi secara operasional dari strategi pengembangan peran penyuluh tidak dapat dilakukan secara parsial, oleh karena itu, perlu ditetapkan faktorfaktor atau kriteria-kriteria yang akan mendukung pelaksanaan strategi tersebut. Berdasarkan hal tersebut, terdapatempat faktoryang perlu dipertimbangkan untuk implementasi strategi pengembangan peran penyuluh yaitu: (1) Dana, (2) Kebijakan, (3) Sumberdaya manusia (SDM), dan (4) Sarana-prasarana. Untuk menentukan strategi prioritas yang akan digunakan, perlu dilakukan analisis terhadap nilai prioritas dari faktor-faktor tersebut di atas. Hasil analisis terhadap faktor-faktor dimaksud disajikan dalam Tabel 5.

Berdasarkan Tabel 5, diperoleh nilai prioritas dari masing-masing faktor mulai dari yang tertinggi yaitu: (1) Sumberdaya manusia (SDM): 1,07; (2) Kebijakan: 1,02; (3) Dana: 0,98; dan (4) Saranaprasarana: 0,93. Sumberdaya manusia (SDM) merupa-kan faktor yang memiliki preferensi tertinggi dalam upaya implementasi kelima strategi yang telah dirumuskan di atas, diikuti berturut-turut kebijakan, dana, dan sarana-prasa-rana. Oleh karena itu, dapat dikatakan bahwa untuk implementasi kebijakan di atas, faktor sumberdaya manusia merupakan hal paling penting yang perlu mendapat perhatian.

Selanjutnya untuk menentukan nilai prioritas terhadap kelima strategi berdasarkan pertimbangan empat faktor di atas, dilakukan analisis nilai prioritas sebagaimana disajikan dalam Tabel 6. Tabel 6 menunjukkan bahwa berdasarkan pertimbangan beberapa faktor, maka diperoleh nilai skala prioritas strategi tertinggi yaitu berturut-turut strategi 1 dengan nilai 4,584, strategi 5 dengan nilai 4,135, strategi 4 dengan nilai 4,129, strategi 2 dengan nilai 3,989, dan strategi 3 dengan nilai 3,887.

Tabel 6 Analisis Nilai Prioritas Strategi berdasarkan Faktor Penentu

Faktor-Faktor Penentu Strategi

\begin{tabular}{|c|c|c|c|c|c|c|}
\hline No & Strategi & Dana & Kebijakan & SDM & Sarana & $\begin{array}{l}\text { Final } \\
\text { Priority } \\
\text { Value }\end{array}$ \\
\hline 1 & $\begin{array}{l}\text { Peningkatan kualitas SDM penyuluh dengan mengikuti } \\
\text { diklat dari instansi lain untuk menambah kemampuan, } \\
\text { pengetahuan, dan keterampilan }\end{array}$ & 1,138 & 1,154 & 1,161 & 1,132 & 4,584 \\
\hline 2 & $\begin{array}{l}\text { Optimalisasi pembangunan pertanian dengan jaminan } \\
\text { peraturan perundangan }\end{array}$ & 0,853 & 1,003 & 1,060 & 1,073 & 3,989 \\
\hline 3 & $\begin{array}{l}\text { Pemanfaatan teknologi yang mendukung dan memperlancar } \\
\text { pelaksanaan program penyuluhan }\end{array}$ & 0,901 & 0,953 & 1,009 & 1,024 & 3,887 \\
\hline 4 & $\begin{array}{l}\text { Pemasaran produk pertanian yang berdaya saing dengan } \\
\text { memaksimalkan peran kelompok tani binaan }\end{array}$ & 1,043 & 1,003 & 1,009 & 1,073 & 4,129 \\
\hline 5 & $\begin{array}{l}\text { Peningkatan kualitas penyuluhan dan sinergitas antar } \\
\text { instansi terkait dengan adanya kejelasan tugas pokok dan } \\
\text { fungsi }\end{array}$ & 0,948 & 1,003 & 1,110 & 1,073 & 4,135 \\
\hline
\end{tabular}




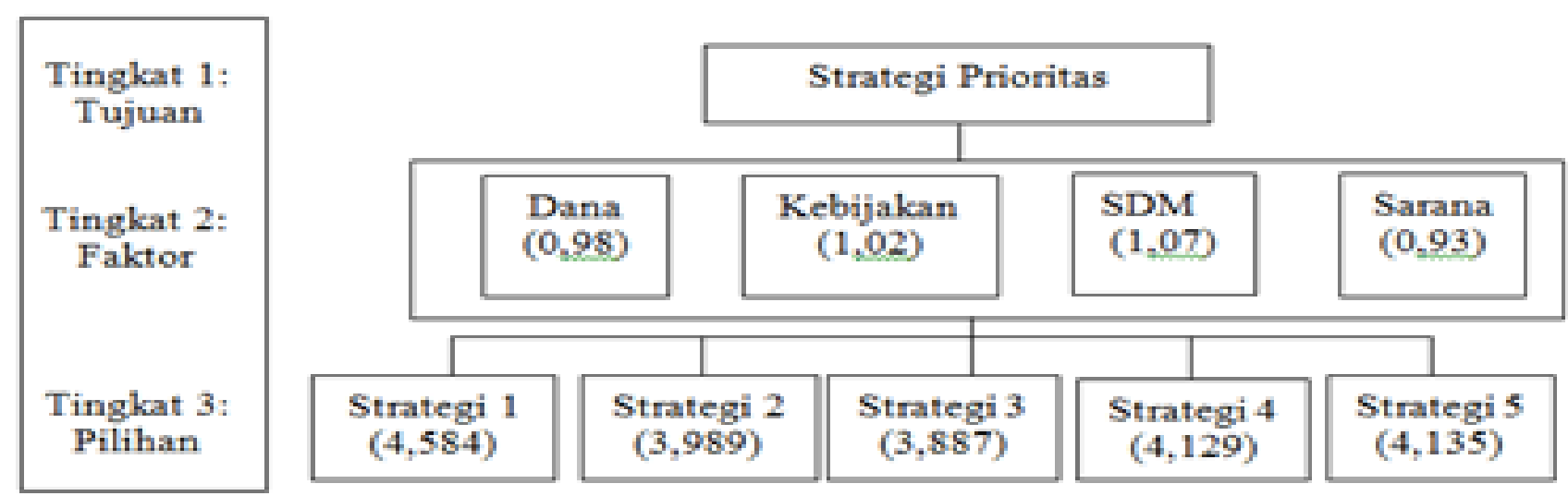

Gambar 4 Diagram Final Proses Analisis Berjenjang

Dari hasil analisis terhadap nilai prioritas stategi beradasarkan pertimbangan faktor-faktor penentu dapat digambarkan dalam diagram hirarki (Gambar 4). Berdasarkan hal tersebut, maka skala prioritas dari kelima strategi yang dapat digunakan untuk mengembangkan peran penyuluh di Provinsi Banten adalah: (a) Peningkatan kualitas SDM penyuluh dengan mengikuti diklat dari instansi lain untuk menambah kemampuan, pengetahuan, dan keterampilan (Strategi 1). (b) Peningkatan kualitas penyulu-han dan sinergitas antar instansi terkait dengan adanya kejelasan tugas pokok dan fungsi (Strategi 5). (c) Pemasaran produk pertanian yang berdaya saing dengan memaksimalkan peran kelompok tani binaan (Strategi 4). (d) Optimalisasi pembangunan pertanian dengan jaminan peraturan perundangan (Strategi 2). (e) Pemanfaatan teknologi yang mendukung dan memperlancar pelaksanaan program penyuluhan (Strategi 3).

\section{Kesimpulan}

Prioritas strategi pengembangan peran penyuluh pertanian lapang di Provinsi Banen adalah: (1) Peningkatan kualitas SDM penyuluh dengan mengikuti diklat dari instansi lain untuk menambah kemampuan, pengetahuan, dan keterampilan; (2) Peningkatan kualitas penyuluhan dan sinergitas antar instansi terkait dengan adanya kejelasan tugas pokok dan fungsi; (3) Pemasaran produk pertanian yang berdaya saing dengan memaksimalkan peran kelompok tanibinaan;(4) Optimalisasi pembangunan pertanian dengan jaminan peraturan perundangan; dan (5) Pemanfaatan teknologi yang mendukung dan memperlancar pelaksanaan program penyuluhan.

\section{Daftar Pustaka}

Dermawan R. 2009. Model Kuantitatif Pengambilan Keputusan danPerencanaan Strategis. Bandung (ID): Alfabeta.

Kartasapoetra AIG. 1994. Teknologi Penyuluhan Pertanian. Jakarta (ID): Bumi Aksara.

Lionberger HF, Gwin PH. 1982. Communication Strategies: A Guide for Agricultural Change Agents. Danville, Illinois: The Interstate Printers \& Publishers, Inc.

Lippitt R, Watson J, Westley B. 1958. The Dynamicsof Planned Change. New York: Harcourt, Brace \& World, Inc.

Mardikanto T. 2009. Sistem Penyuluhan Pertanian. Edisi Pertama. Surakarta (ID): Sebelas Maret University Press.

Mosher AT. 1987. Menggerakkan dan Membangun Pertanian. Jakarta (ID): Yasa Guna.

Padmowihardjo S. 2004. Menata Kembali Penyuluhan Pertanian di Era Pembangunan Agribisnis. Jakarta (ID): Departemen Pertanian.

Rangkuti F. 2008. Analisis SWOT Teknik Membedah Kasus Bisnis: Reorientasi Konsep Perencanaan Strategis untuk Menghadapi Abad 21. Jakarta (ID): Gramedia.

Rogers EM. 2003. Diffusion of Innovations.5th Ed. New York: Free Press.

Sevilla CG, Ochave JA, Punsalan TG, Regala BP, Uriarte GG. 1993. Pengantar Metode Penelitian. Jakarta (ID): UI Press.

[YPST] Yayasan Pengembangan Sinar Tani. 2001. Penyuluhan Pertanian. Jakarta (ID): Yayasan Pengembangan Sinar Tani. 